\title{
Effect of Some Additiveson Mechanical and Physical Properties of Cob Building in Iraq
}

\author{
Manar Nazar Ahmed ${ }^{1}$, Payman Sahbah Ahmed ${ }^{2}$, Samal Osman Saied ${ }^{3}$ \\ ${ }^{1,3}$ Architectural Engineering Department, Koya University, Koysinjaq, Kurdistan, Iraq \\ ${ }^{2}$ Manufacturing Engineering Department, Koya University, Koysinjaq, Kurdistan, Iraq
}

\begin{abstract}
Construction materials needs to be low energy consuming and mud construction system is less energy consuming and very successful in different weather conditions. Cob is an old earth building method passed down through the millennia, Cob is a sustainable earth building material with mud soil, coarse sand, straw and water are thoroughly combined and beaten together. This research aims to study the effect of some additives on physical properties (thermal conductivity and water content \%) and mechanical property (compression strength) of Cob. These additives are: polymethyl methacrylate (PMMA) grains, hooked end steel fibers (HESF), wood as sawdust (SDW) and goat hair fibers (GHF), with 2 and $4 \%$ by weight as the percentages of additives. Results shows that (PMMA) improves the insulation of Cob to maximum values compared to other additives in both 2 and $4 \%$ followed by $(S D W)$ and $(G H F)$ respectively. All additive materials improve the compressive strength of Cob but with different extents depending on the water content. (GHF) is the best material to improve the compressive strength of Cob followed by (HESF) and (PMMA) respectively while adding (SDW) will lead to reverse effect i.e. decreasing the compressive strength.
\end{abstract}

Keywords: Cob, thermal conductivity, compressive strength, goat hair, hooked end steel fiber, PMMA.

\section{Introduction}

Architecture requires use of diverse construction materials that require a special constructionmethods. But most of these construction methods are energy concentrated. All the traditional resources are consuming which has made it compulsoryto choose materials and construction systemswhich require less energy for its performance. Mud construction system is less energy consuming and verysuccessful in different weather conditions. Earth is one of man's oldest building materials and most oldcivilizations used it in some form. It was easily available, cheap, and strong and needed only simple technology [1] in addition to its excellent sustainable characteristics [2].Some of the method utilized for earth building construction around the world incorporate utilizing mud bricks dried by the sun (earth brick), wet soil placed between removable form boards (rammed earth), wet mud soil mixed with straw placed by hand to form walls (Cob), or clay reinforced with woven or liadwood (wattle and daub) [3].

Cob is an old English word that means lump or rounded mass [4] or the English name for mudwall [2]. Cob is an old earth building method passed down through the century and known by many names in many countries.Basically, Cob is building with mud. Clay soil, coarse sand, straw and water are thoroughly combined and beaten together. This stiff mud is thenbuilt up into walls while still wet on a foundation of stone and lean of concrete.The mixture is applied in feeds, each of which is "stitched" into the onebelow while both are still flexible. As the bottom of thewall becomes strong and dry, more Cob is added on top until the desired height is reached, with doors, windows, plumbing, electrical conduits, wooden anchors for cabinets,etc., being built in the same time. The roofs made from beam of wood covered with tibial and Cob as shown in figure 1. Walls then covered with mortar of cement as a final step after Cob is dried. The result is a very hard, strong, homogenous earth wall, strengthen by a continuous interwoven matrix of high tensile-strength straw fibers suitable for rural areas in Iraq.
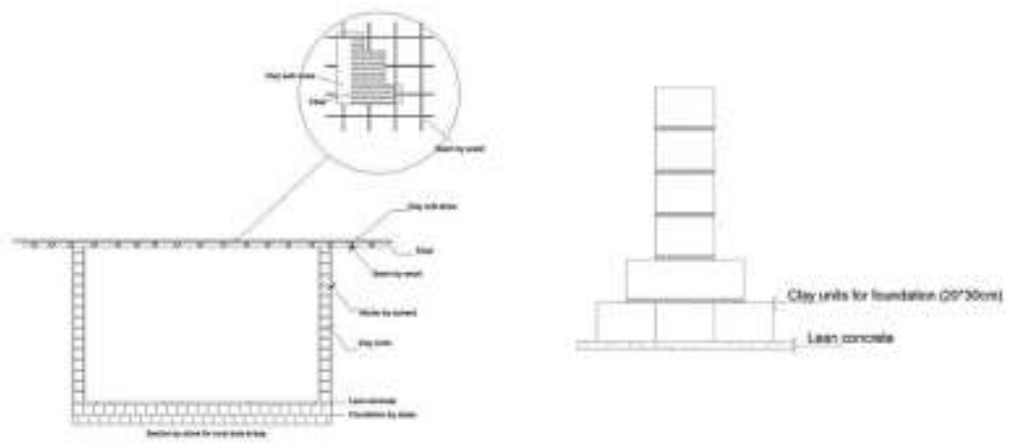

Fig. 1.Section by Cob for rural areas in Iraq (left)construction of wall (right)- Drawn by authors. 
M. N. Ahmed and P. S. Ahmed improved the compression strength of Cob by substituting certain percentage of Cob with a number of low cost materials and materials' waste, the reinforcing materials are: polyethylene fibers, human hair, shredded packaged drinking water cups, glass waste, kibbled glass waste, steel, and gypsum. Soil strength is studied in addition to water content of the reinforced samples. Results showed that Gypsum gives the highest compression strength value among all reinforcement used in this study and adding kibbled glass waste and packaged drinking water cup decreases the compression strength of Cob [5].

Akinwumi II took earth building materials from three villages: Oka, Use and Uselu and conducted a laboratory test on the soil samples to classify them.laboratory tests include: natural moisture content, sieve and hydrometer analysis, and Atterberg limits tests. Laboratory tests showed that soil samples in the three locations were suitable for mud house construction. The construction methods used in above villages is similar in procedures to that of Cobconstruction, except that straw is not added [3].

Enrico Quagliarini et. al. tried to re-usethe Cob technique for construction and for how to accurately work on it for a suitable and sustainable conservation.the results of this study have found a suitable soil for future possible suitable restoring involvement on the investigated case study at Macerata, re-using the same old building technique, which is the most compatible involvement [6].

This work aims to study the effect of some additives on physical properties (watercontent\% and thermal conductivity) and mechanical property (compression strength) of Cob. These additives are: polymethyl methacrylate (PMMA) grains, hooked end steel fibers (HESF), wood as sawdust (SDW) and goat hair fibers (GHF), with 2 and $4 \%$ by weight as the percentages of additives.

\section{Experimental Part}

Initially, Haibat Sultan mountain soil in koysinjaq in Kurdistan - Iraq with water and straw in 5:1 ratio are used to produce Cob samples, Properties of soil are as follows: water content $=27.76 \%$, liquid limit $=27.8 \%$, plastic limit $=25.4 \%$ and plasticity index $=2.37 \%$ [5] according to ASTM D4318 [7] and ASTM D698 [8].

Cob is substituted by a number of synthetic and natural materials to study their effect on Cob's physical and mechanical properties, these materials are: polymethyl methacrylate (PMMA) grains, hooked end steel fibers (HESF), wood as sawdust (SDW) and goat hair fibers (GHF) figure 2 and the substitution amount is 2, 4 weight percentage wt.\%.

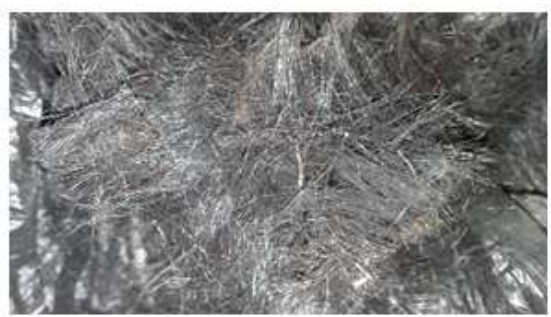

GHF

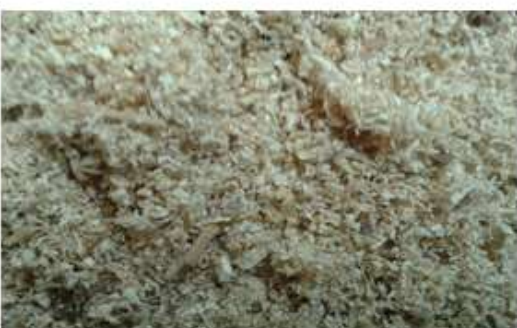

SDW

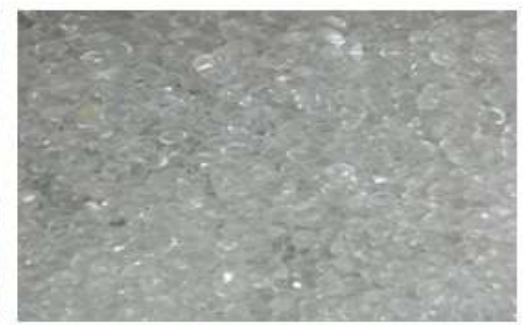

PMMA

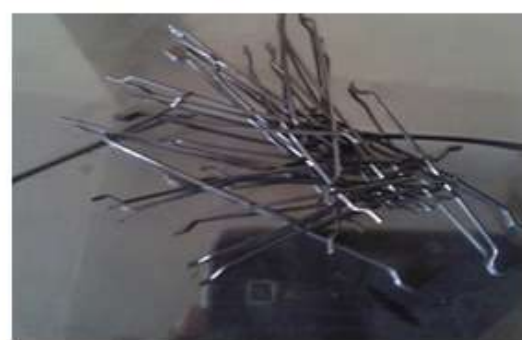

HESF

Fig. 2. Additive materials used in this research.

Then samples are sun-dried, water content is measured after 10 days.Thermal conductivity (ASTMD5334 [9]) (figure 3) and Compression strength (ASTM E9-09 [10]) (figure 4) have been measured for samples and compared with the Cob without any additives. 


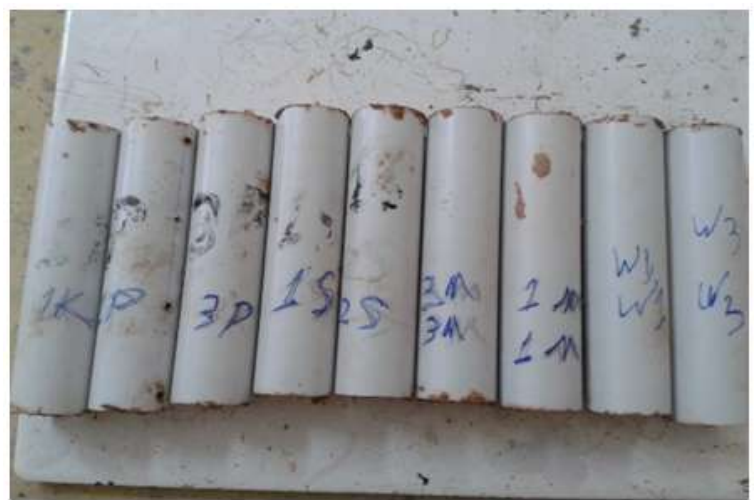

Fig. 3. Thermal conductivity samples used in thisresearch.

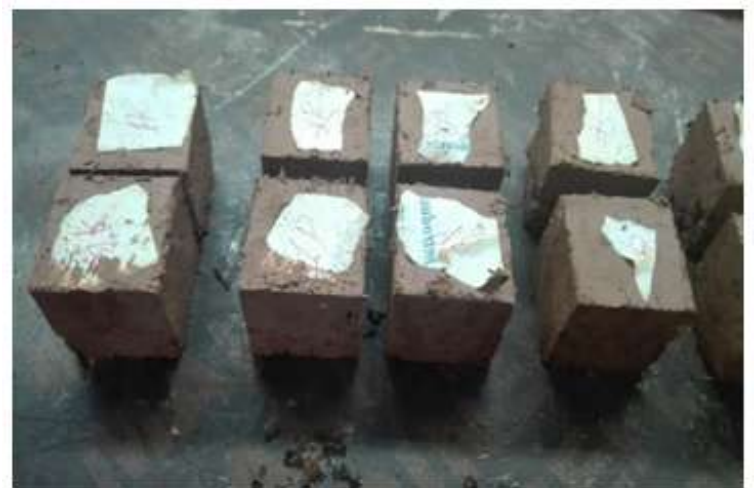

Fig. 4. Compressive strength samples used in this research.

\subsection{Results of Thermal Conductivity}

\section{Results andDiscussion}

Figures 5 and 6 shows thermal conductivity test results of Cob with 2 and $4 \%$ additives, it can be seen that all kinds of additives improve the insulation of Cob except (HESF), this can be related to the thermal conductivities of the additives where the thermal conductivity of (PMMA) is within the range of $(0.167-0.25)$ $\mathrm{W} / \mathrm{m} . \mathrm{K}$ [11] in addition to the uniform structure of (PMMA)grains acts as obstacle against heat flow which results in lowering the conductivity of Cob. Addition of (HESF) decreases the insulation of Cob because of thermal conductivity of the steel is within the range (36-54) W/m.K [12] which results in increasing the thermal conductivity of Cob. Addition of (SDW) increases the insulation of Cob because of thermal conductivity of the sawdust wood is $(0.084) \mathrm{W} / \mathrm{m} . \mathrm{K}$ [13] which results in decreasing the thermal conductivity of Cob. Addition of (GHF) increases the insulation of Cob because of thermal conductivity of the hair is within the range $(0.37$ $0.475) \mathrm{W} / \mathrm{m} . \mathrm{K}[14]$ which results in decreasing the thermal conductivity of Cob.

Figures 7 shows curves of thermal conductivity test results of Cob with 2 and $4 \%$ additives together for all additives, it can be seen that the (PMMA) decreases the thermal conductivity to minimum values compared to other additives in both 2 and $4 \%$ followed by (SDW) and (GHF) respectively, which makes the (PMMA) the best material to improve insulation of Cob.

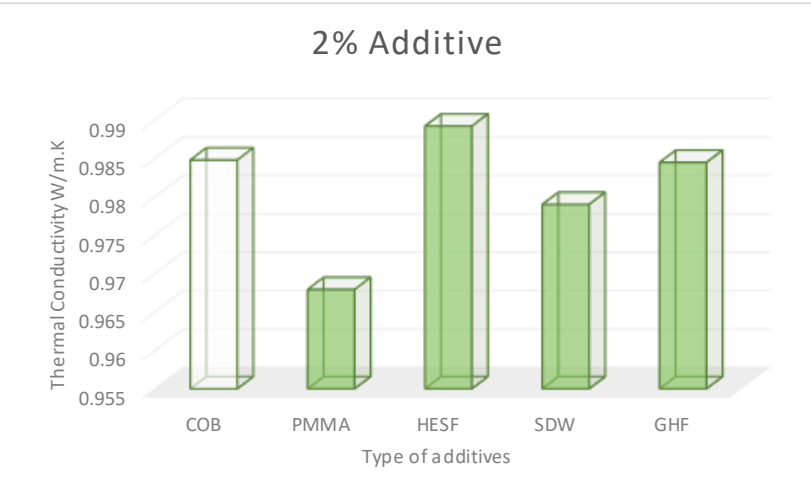

Fig. 5. Comparison of Thermal Conductivity Test Results of Cob with 2\% Additives 


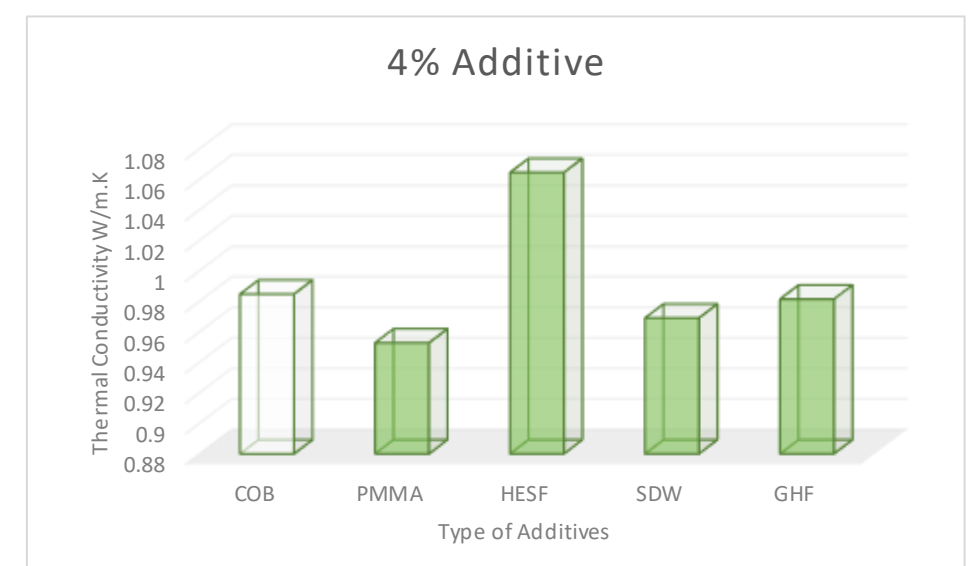

Fig. 6. Comparison of Thermal Conductivity Test Results of Cob with 4\% Additives.

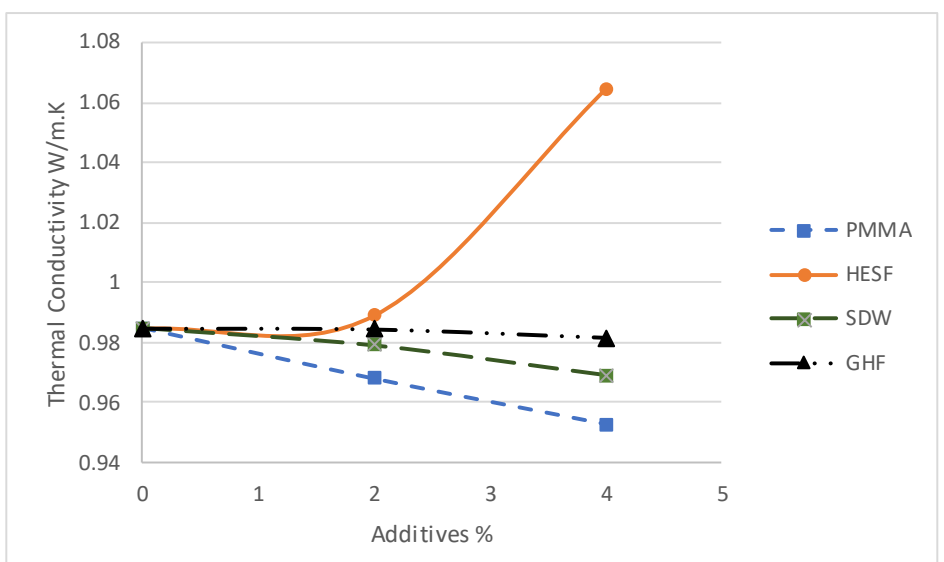

Fig.7. Curves of Thermal Conductivity Test Results of Cob with 2 and $4 \%$ Additives.

\subsection{Results of Compressive Strength and Water Content}

Figure 8 and 9 shows the compressive strength test results with $2 \%$ additives, it can be seen that all additive materials improve the compressive strength of Cob but with different extents, the uniform structure of (PMMA) grains make the compressive load distributed evenly on the Cob samples which leads to improve the compressive strength in addition to relatively low water content as can be seen in figure 9 . The hooked end design of steel fiber leads to increase samples' strengthening and support against the compressive strength load in addition to the low water content (as can be seen in figure 9) both results in increasing compressive strength. High water absorption and content of sawdust wood as shown in figure 9 leads to relatively low increase in compressive strength of Cob.Addition of (GHF) leads to increase the compressive strength of Cob to relatively high extentbecause the fibers are arranged evenly in the material and compression load distributed equally on the sample in addition to low water content as can be seen in figure 9. The obtained compressive strength by adding $2 \%$ of $(\mathrm{GHF})$ is higher than the obtained value by adding $2 \%$ gypsum in the previous work of authors [5].

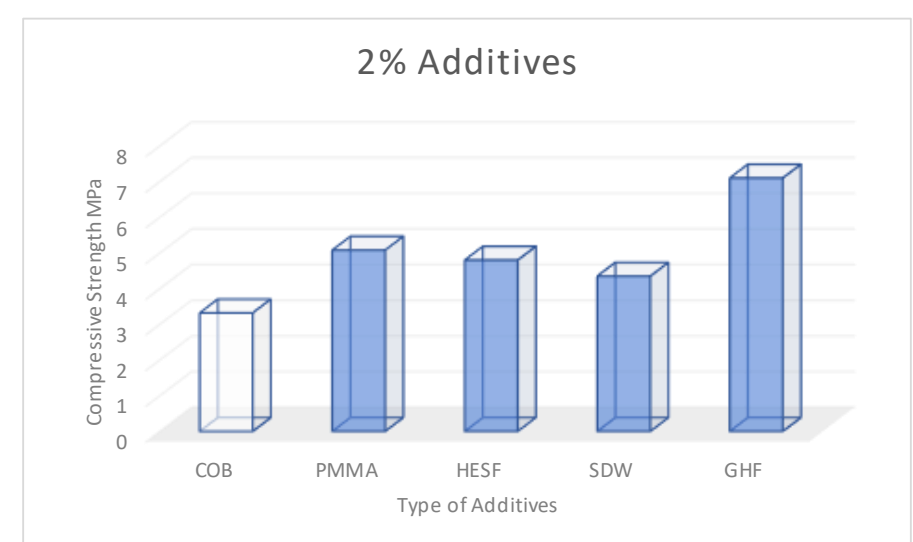

Fig. 8. Comparison of Compressive Strength Test Results of Cob with 2\% Additives. 


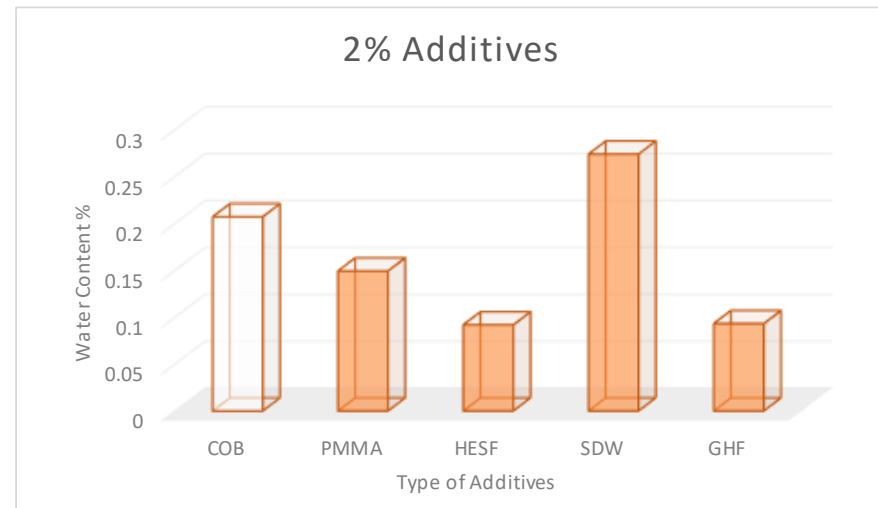

Fig. 9. Comparison of WaterContent Test Results of Cob with 2\% Additives.

Figure 10 and 11 shows the compressive strength and water content test results with $4 \%$ additives, it can be seen that increasing the percentages of all additive materials improve the compressive strength of Cob but with different extents depending on the water content, the higher percentages and the uniform structure of (PMMA) grains make the compressive load distributed evenly on the Cob samples which leads to more improvement in the compressive strength in addition to relatively low water content as can be seen in figure 11. The higher percentages and hooked end design of steel fiber leads to more increase in samples' support against the compressive strength load in addition to the low water content (as can be seen in figure 11) which results in increasing compressive strength. The very high water content of sawdust wood (as shown in figure 11) leads to relatively low increase in compressive strength of Cob. Addition of (GHF) leads to more increase the compressive strength of Cob to relatively high extent because the fibers are arranged evenly in the material and compression load distributed equally on the sample in addition to low water content(as can be seen in figure 11). The obtained compressive strength by adding $4 \%$ of (GHF) is higher than the obtained value by adding $4 \%$ gypsum in the previous work of authors [5].

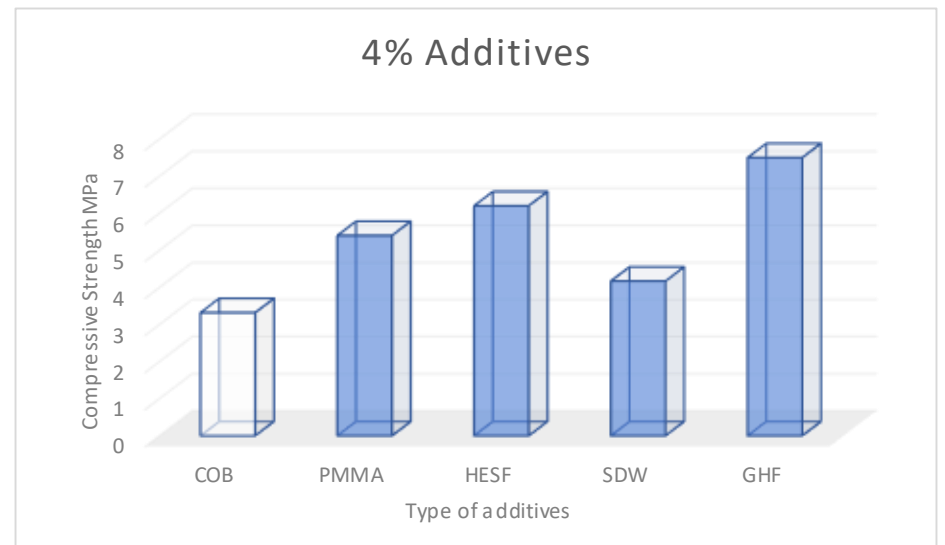

Fig. 10. Comparison of Compressive Strength Test Results of Cob with 4\% Additives.

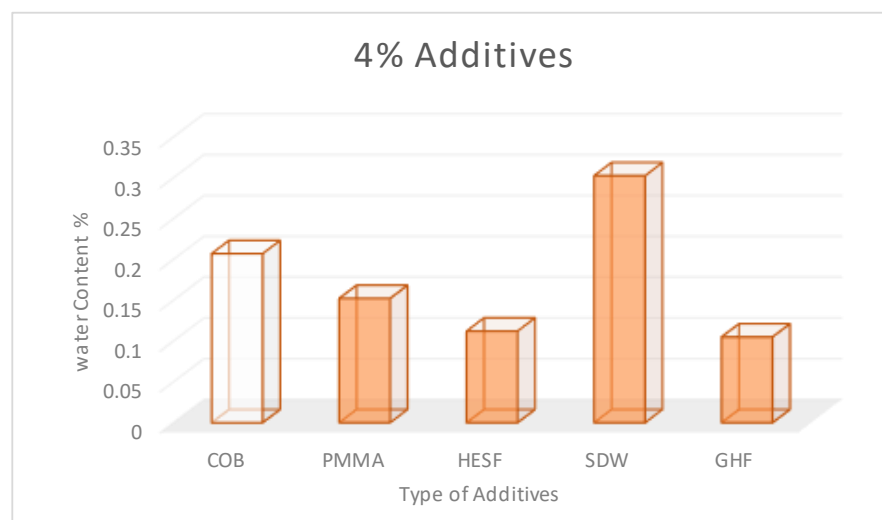

Fig. 11. Comparison of WaterContent Test Results of Cob with 4\% Additives. 
Figure 12 shows curves of compressive strength test results of Cob with 2 and $4 \%$ additives it can be seen that the relation between the compressive strength and additives percentages are linear in (HESF) which means that increasing the percentages in future will lead to high increase in the compressive strength, while the relation is parabolic with small increase in the case of (GHF) and (PMMA) which means that increasing the percentages of these additives in future will lead to low increase in the compressive strength. the relation between the compressive strength and additives percentages of (SDW) is parabolic with small decrease which means that increasing the percentages of these additives in future will lead to low decrease in the compressive strength. From this discussion, it could be said that (GHF) is the best material to improve the compressive strength of Cob followed by (HESF) and (PMMA) respectively while adding (SDW) will lead to reverse effect i.e. decreasing the compressive strength.

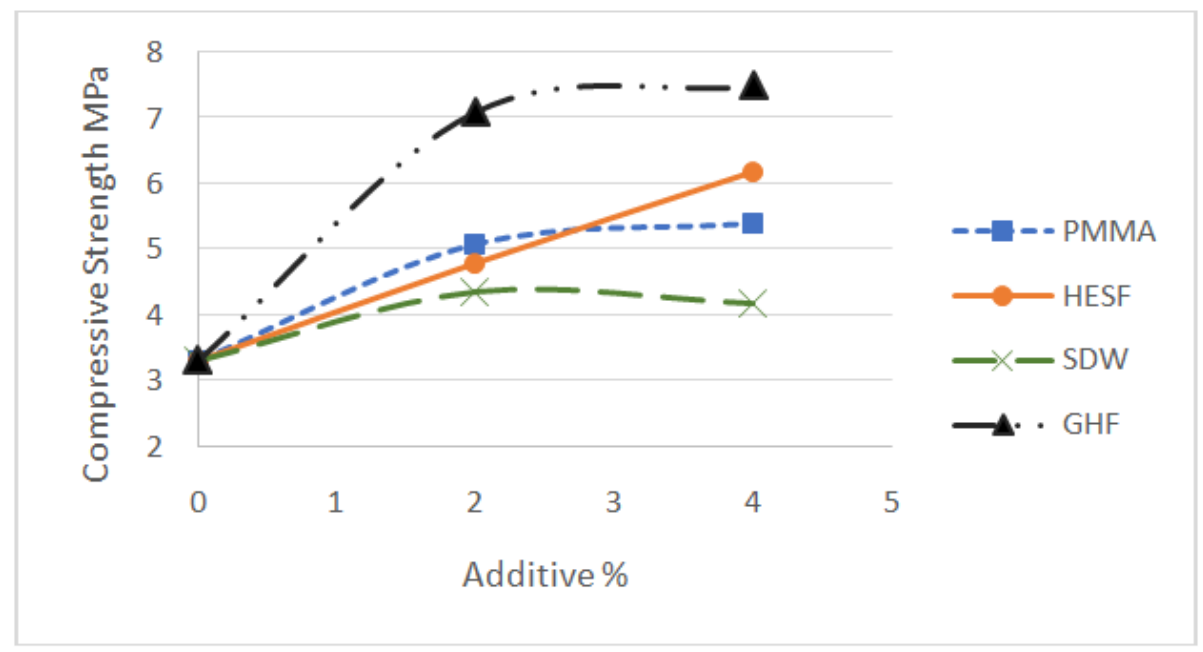

Fig. 12. Curves of Compressive Strength Test Results of Cob with 2 and $4 \%$ Additives.

\section{Conclusions}

1. All kinds of additives improve the insulation of Cob except (HESF).

2. (PMMA) decreases the thermal conductivity to minimum values compared to other additives in both 2 and $4 \%$ followed by (SDW) and (GHF) respectively, which make the (PMMA) addition is the best material to improve insulation Cob.

3. All additive materials improve the compressive strength of Cob but with different extents depending on the water content

4. Relation between the compressive strength and additives percentages are linear in (HESF) which means that increasing the percentages in future will lead to high and rapid increase in the compressive strength.

5. Relation is parabolic with small increase in the case of (GHF) and (PMMA) which means that increasing the percentages of these additives in future will lead to low and gradual increase in the compressive strength.

6. Relation between the compressive strength and additives percentages of (SDW) is parabolic with small decrease which means that increasing the percentages of these additives in future will lead to low decrease in the compressive strength.

7. (GHF) is the best material to improve the compressive strength of Cob followed by (HESF) and (PMMA) respectively while adding (SDW) will lead to reverse effect i.e. decreasing the compressive strength.

\section{References}

[1] Sruthi G S:" Mud architecture", International Journal of Innovative Research in Science, Engineering and Technology, Vol. 2, Special Issue 1, pp.47-52, (2013).

[2] Becky Little and Tom Morton: "Building with earth in Scotland: innovative design and sustainability", Scottish Executive Central Research Unit, (2001).

[3] Akinwumi II:" Earth building construction processes in Benin city, Nigeria and engineering classification of earth materials used", Indian Journal of Traditional Knowledge, Vol.13, No.2, pp.686-690, (2014).

[4] Mariana Estrada: "A case study of Cob earth based building technique in Matagalpa, Nicaragua - LCA perspective and rate of adoption", MSc thesis, Mid Sweden University, (2013).

[5] ManarNazar Ahmed and Payman Sahbah Ahmed: "Improving sustainable building materials by adding wastes and low cost reinforcements", International Journal of Engineering Technology, Management and Applied Sciences, Vol. 4, Issue 9, pp.181-191, (2016).

[6] Enrico Quagliarini, Alessandro Stazi, ErioPasqualini and Evelina Fratalocchi: "Cob construction in Italy: some lessons from the past", Journal of Sustainability, Vol. 2, pp.3291-3308, (2010). 
[7] ASTM D4318 - standard test method for liquid limit, plastic limit, and plasticity index of soils.

[8] ASTM D698 - standard Test Methods for Laboratory Compaction Characteristics of Soil Using Standard Effort (12,400 $\mathrm{ft}^{-1 b s / \mathrm{ft}^{3}}$ $\left.\left(600 \mathrm{KN}-\mathrm{m} / \mathrm{m}^{3}\right)\right)$.

[9] ASTM5334 - Standard Test Method forDetermination of Thermal Conductivity of Soil and SoftRock by Thermal Needle Probe Procedure.

[10] ASTM E9 - 09 - standard test method for compression testing of metallic materials at room temperature.

[11] Internet: www.mit.edu/ 6.777/matprops/pmma.htm.

[12] Internet: https://en.wikipedia.org/wiki/List_of_thermal_conductivities.

[13] Internet: http://www.engineeringtoolbox.com/thermal-conductivity-d 429.

[14] Lillywhite HB, Stein BR:"Surface sculpturing and water retention of elephant skin", Journal of Zoology, No. 211, pp: 727734,(1987). 